\title{
Polimorfismo floral e suas implicações em sistemas sexuais: o caso de Solanum melongena (Solanaceae)
}

Floral polymorphism and its implications for sexual systems: the Solanum melongena (Solanaceae) case

\author{
Vivian Zambon ${ }^{1}$ \& Kayna Agostini ${ }^{2,3}$
}

\begin{abstract}
Resumo
O sucesso reprodutivo das plantas pode estar relacionado a diversos fatores. Dessa forma, o presente trabalho teve como objetivo analisar os diferentes morfos florais apresentados por Solanum melongena (híbrido Nápoli) no contexto da biologia reprodutiva e da polinização. O estudo foi realizado em Estiva Gerbi, São Paulo. Os dados de morfometria floral foram coletados com auxílio de paquímetro manual e estereomicroscópio. Para determinar o sistema reprodutivo, verificou-se a formação de tubos polínicos em diferentes horários após a polinização manual ser efetuada. Realizou-se a caracterização dos visitantes florais através de observações de campo e calculou-se a frequência dos mesmos. Constatou-se diferença significativa entre o tamanho das corolas e dos estiletes dos diferentes morfos, não diferindo entre si apenas as anteras. Quanto aos sistemas reprodutivo e sexual, detectou-se que $S$. melongena é uma espécie xenógama facultativa, assim como apresenta o fenômeno da andromonoicia, no qual as flores de estilete curto apresentam apenas a função masculina funcional. Concluise para $S$. melongena que ambos os morfos contribuem para seu sucesso reprodutivo, assim como a ação dos polinizadores, pois embora apresente certo grau de autocompatibilidade, a autopolinização não mostrou-se suficiente para uma efetiva fecundação de seus óvulos como quando na ocorrência da polinização cruzada. Palavras-chave: andromonoicia; sistema reprodutivo; visitantes florais.
\end{abstract}

\begin{abstract}
The reproductive success of plants may be related to several factors. Thus, this study aimed to analyze the different floral morphs presented by Solanum melongena in the context of reproductive biology and pollination. The study was conducted in Estiva Gerbi, São Paulo. Data on floral morphometry were collected with the aid of a manual caliper and stereomicroscope. To determine the reproductive system, the formation of pollen tubes at different times after manual pollination was observed. The characterization of floral visitors was conducted through field observations, and the frequency of their visits was calculated. There was a significant difference in size between the corollas and styles from different morphs, while only the anthers did not differ significantly. Regarding the sexual and reproductive systems, it was found that S. melongena is a facultative xenogamous species, and presents the andromonoecy phenomenon in which short-styled flowers are only functionally male. The conclusions were that, for S. melongena (hybrid Napoli), both of its floral morphs, as well as the action of its pollinators, contribute to the reproductive success of this species, as, even though it has a certain degree of self-compatibility, self-pollination was not sufficient for a fertilization of ovules as efficient as the one in cross-pollination.
\end{abstract}

Key words: andromonoicy; reproductive system; floral visitors.

\footnotetext{
${ }^{1}$ Universidade Estadual de Campinas - Unicamp, Inst. Biologia, Prog. Pós-graduação em Biologia Vegetal - PPG-BV, R. Monteiro Lobato 255, Cidade Universitária Zeferino Vaz, 13083-862, Campinas, SP, Brasil.vizambon@yahoo.com.br, zambonvivian@gmail.com

${ }^{2}$ Universidade Federal de São Carlos - UFSCar, Centro de Ciências Agrárias, Depto. Ciências da Natureza, Matemática e Educação, Rod. Anhanguera Km 174, 13600-970, Araras, SP, Brasil.

${ }^{3}$ Autor para correspondência: kaynaagostini@gmail.com
} 


\section{Introdução}

Grande parte das angiospermas apresenta flores bissexuadas, característica que facilita a ocorrência de dois importantes processos para a reprodução das plantas: a otimização da polinização, através da coleta e deposição de grãos de pólen em uma única visita do polinizador e, por outro lado, a facilitação da autogamia (Teixeira et al. 2014). Assim, de forma a reduzir tal processo, algumas estratégias reprodutivas são apresentadas pelas plantas, como a hercogamia, o polimorfismo floral e mecanismos genéticos de autoincompatibilidade, que podem atuar como uma barreira espacial e fisiológica para a autopolinização (Barrett et al. 2000; Oliveira \& Maruyama 2014).

O gênero Solanum apresenta flores tipicamente bissexuadas, no entanto algumas espécies podem apresentar diferentes morfos florais, que acarretam em distintos sistemas sexuais. Espécies monóicas e algumas variações como andromonoicia e diocia - que conferem ao indivíduo flores com morfologias semelhantes e funções distintas - já foram relatadas para o gênero (Forni-Martins et al. 1998). As flores de Solanum melongena apresentam um polimorfismo floral caracterizado por uma diferença gradativa no tamanho do estilete, que pode se apresentar abaixo, no mesmo nível (condição rara) ou acima do nível das anteras (Kowalska 2008). Por se tratar de uma espécie cultivada, possui diversos híbridos, cultivares e variedades locais nos países onde é produzida, o que também pode resultar em uma ampla diversidade de genótipos (Aramendiz-Tatis et al. 2011).

Outra característica floral importante no gênero Solanum é a ocorrência de anteras com deiscência poricida, como na espécie $S$. melongena, de forma que o pólen é liberado através de poros apicais. Essa característica floral favorece visitantes com comportamento de vibração, o qual é mais comumente realizado por abelhas de grande porte (Buchmann \& Hurley 1978). E, ainda que uma gama de espécies de plantas, pertencentes a distintas famílias - Myrtaceae, Cistaceae, Papaveraceae - e com morfologias florais variadas revelem que a polinização vibrátil não está associada a um único tipo de morfologia floral, o gênero Solanum se destaca nesse aspecto (De Luca \& Vallejo-Marín 2013).

Nessa perspectiva, o sucesso reprodutivo de $S$. melongena pode estar relacionado tanto ao comportamento das espécies de visitantes florais, quanto à variação floral dentro de um mesmo indivíduo da espécie. Assim, o presente trabalho teve como objetivo analisar os diferentes morfos florais de $S$. melongena no contexto da biologia reprodutiva e da polinização, para responder as seguintes questões: 1) Levando-se em conta a existência de dois morfos florais em $S$. melongena, existem diferenças em aspectos da biologia floral e da morfoanatomia entre os verticilos vegetativos e reprodutivos de ambos? 2) Como cada morfo floral contribui para o sucesso reprodutivo da espécie? e 3) A riqueza de visitantes florais está relacionada à morfologia floral apresentada por S. melongena?

\section{Material e Métodos}

Área e sistema de estudo

$\mathrm{O}$ estudo foi realizado em área de cultivo agrícola convencional, em uma propriedade agrícola de exploração comercial de berinjela (Solanum melongena - híbrido Nápoli), localizada no município de Estiva Gerbi (22¹6'20,73"S, 4656'46,17'O), região leste do estado de São Paulo. O plantio estava instalado na "Fazenda Cercado Grande", com área total de 7.370 ha e cerca de 23.000 indivíduos da espécie, perfazendo um total de 4,5 ha de área plantada. $\mathrm{O}$ cultivo de berinjela ocorreu de forma isolada, não havendo consórcio com outras culturas agrícolas e a aplicação de inseticidas era efetuada semanalmente, entretanto tal prática ocorria em horários de baixa frequência de visitantes florais, como finais de tarde.

Os produtores agrícolas mantiveram o plantio no mesmo local pelo período de um ano, substituindo a cultura após esse intervalo e realocando a cultura da berinjela para outra área. Outras culturas cultivadas na região são as do tomate, milho e feijão (IBGE 2015). O clima da região é tropical com estação seca de inverno (Aw) e as temperaturas médias no período de verão são em torno de $24^{\circ} \mathrm{C}$ e mínimas próximas de $16^{\circ} \mathrm{C}$, tendo dessa maneira, seus maiores índices de chuva nos meses de dezembro, janeiro e fevereiro, totalizando anualmente uma precipitação média em torno de $1.300 \mathrm{~mm}$ (Setzer 1976).

Solanum melongena (híbrido Nápoli) possui porte arbustivo, com caule do tipo semi-lenhoso e ereto, atingindo de 1 a 3 metros de altura. É uma planta perene, com flores pentâmeras e bissexuais, podendo ser solitárias ou distribuídas em inflorescências do tipo cimeira. $\mathrm{O}$ único recurso floral oferecido é o pólen, coletado geralmente 
por abelhas fêmeas que utilizam esse recurso na alimentação das larvas (Antonini et al. 2002). Os frutos são do tipo baga, geralmente de formato oblongo, brilhantes e de coloração variada, sendo a de coloração roxo-escuro e pedúnculo verde a mais comum no Brasil (Ribeiro et al. 1998).

\section{Morfometria floral}

Os dados de morfometria floral foram coletados com auxílio de paquímetro manual e de estereomicroscópio. Por se tratar de uma espécie com flores actinomorfas, foi medido apenas o comprimento total da corola, assim como a altura do estilete e das anteras de flores de estilete curto $(n=30)$ e flores de estilete longo $(n=30)$, que ocorrem juntamente em um mesmo indivíduo. As diferenças entre as medidas nos dois morfos florais foram testadas através do teste $\mathrm{t}$ ao nível de significância de 0,05 , posteriormente ao teste Kolmogorov-Smirnov de normalidade dos dados. Utilizou-se o software Statistica Six.

\section{Microscopia eletrônica de varredura (MEV)}

Para a análise dos verticilos florais dos distintos morfos de $S$. melongena, foram utilizadas flores $(\mathrm{n}=10$, sendo 5 flores de estilete curto e 5 flores de estilete longo) fixadas em FAA (5\% de formalina, 5\% de ácido acético e 90\% de álcool etílico a 50\%), desidratadas em série de álcool $(10 \%, 30 \%, 50 \%$ e $70 \%$ estoque) e acetona $(90 \%$ e $100 \%)$. As amostras foram submetidas ao ponto crítico para retirada de toda água estrutural, utilizando-se o equipamento Balzers Critical Point Dryer 030. Posteriormente, foram recobertas com ouro pelo método de "Sputtering", com o equipamento Balzers Sputter Coater 050. As micrografias foram obtidas em microscópio eletrônico de varredura Hitachi TableTop Microscope TM3000, operando a $15 \mathrm{kV}$.

\section{Biologia floral e visitantes}

Flores de $S$. melongena foram observadas quanto ao horário e período da antese. Para tanto, flores de estilete curto $(n=5)$ e flores de estilete longo $(n=5)$ em pré-antese foram ensacadas e observadas até a senescência. Ao longo da antese observou-se a coloração das flores, a duração da flor receptiva e doadora de pólen viável, a receptividade do estigma e a presença de osmóforos. Os indivíduos também foram observados, de forma a contabilizar as inflorescências, as flores e a proporção dos diferentes morfos florais $(n=10)$.
A estimativa da produção de pólen se deu através da contagem do número de grãos de pólen produzidos por antera. Para isso, flores em préantese e em antese - não ensacadas, disponíveis para os visitantes florais - foram coletadas em intervalos de 3 horas, em um período total de 12 horas (das $6 \mathrm{~h}$ às $18 \mathrm{~h})$. Em cada intervalo, foram coletadas cinco flores, totalizando ao final do período 20 flores. As anteras foram analisadas ainda frescas, no mesmo dia da coleta, a partir da montagem de lâminas e posterior contagem dos grãos de pólen em microscópio de luz. Para cada flor, os grãos de pólen de uma antera eram contabilizados e a partir desse valor, estimava-se o total de grãos/flor. Para averiguar a relação entre a frequência dos visitantes florais e a disponibilidade de pólen, foi calculado o coeficiente de correlação de Pearson (r) (Statistica Six Sigma).

De forma a caracterizar os aspectos ocorrentes na viabilidade polínica e na receptividade do estigma ao longo da antese, utilizou-se nessas análises flores em diferentes estágios de desenvolvimento, que foram definidos de acordo com o tempo ocorrido após a mesma. Assim, o primeiro estágio corresponde ao período de pré-antese (botão); o segundo estágio ao período em que ocorre a antese floral; o terceiro estágio de 24 a 36 horas após a antese; e o quarto estágio após 36 horas do momento da antese.

Para analisar a viabilidade polínica, foi utilizada a técnica de coloração com carmim acético a $2 \%$, que cora o protoplasma celular nos grãos de pólen (Radford et al. 1974). Para se obter uma amostragem ao acaso dos grãos de pólen corados, usou-se o método de varredura, sendo contabilizados 100 grãos de pólen/lâmina. Foram utilizadas nesta análise flores de estilete curto $(n=20)$ e flores de estilete longo $(n=20)$. A normalidade dos dados foi verificada através do teste de Kolmogorov-Smirnov. O teste estatístico não paramétrico Kruskal Wallis foi utilizado para analisar as diferenças entre os estágios de desenvolvimento da flor e estes dados foram comparados pelo teste de Dunn, através do software Action 2.7.

A receptividade do estigma foi analisada através do teste de peroxidase, utilizando peróxido de hidrogênio $\left(\mathrm{H}_{2} \mathrm{O}_{2}\right)$. A indicação do estigma receptivo se deu através da liberação de bolhas de $\mathrm{O}_{2}$ no mesmo, o que foi observado com auxílio de uma lupa de campo (Kearns 1997). Esse teste foi aplicado em flores de estilete curto $(n=10)$ e flores de estilete longo $(n=10)$. Para verificar a presença de osmóforos nas flores, foi realizado o teste do 
vermelho neutro (Dafni 1992). Flores frescas foram coletadas aleatoriamente $(\mathrm{n}=10)$ e submersas em solução do corante utilizado durante 60 minutos e, logo após esse procedimento, lavadas em água destilada e observadas sob estereoscópio. As regiões florais coradas em vermelho intenso apontaram a presença de osmóforos.

Os visitantes florais foram observados durante as atividades de forrageamento ao longo do período de floração de $S$. melongena, entre fevereiro e junho de 2014. As observações e coletas dos mesmos ocorreram nos períodos da manhã (das $6 \mathrm{~h}$ às $12 \mathrm{~h}$ ) e da tarde (das $13 \mathrm{~h}$ às $16 \mathrm{~h}$ ) e totalizaram 50 horas, divididas igualmente em cinco dias (10 horas/dia). Em cada dia, 5 transectos de aproximadamente 10 metros - delimitados aleatoriamente, de forma a abranger toda a área plantada - eram observados. As observações ocorreram de maneira sistemática, isto é, durante cada período de 2 horas, as mesmas eram realizadas em um dos transectos delimitados anteriormente.

A frequência dos visitantes florais foi calculada através do percentual do número de visitas de cada espécie em relação ao total visualizado: $\mathrm{F}=(\mathrm{ni} / \mathrm{N}) \times 100$, onde $\mathrm{ni}=$ número de visitas da espécie i e $\mathrm{N}=$ número total de visitas (Vilhena \& Augusto 2007). A caracterização dos visitantes florais através de observações de campo, complementadas com a análise de fotografias e vídeos, também foi efetuada. Concomitantemente às observações, coletou-se indivíduos das espécies visitantes para identificação taxonômica, realizada com auxílio de chaves de identificação específicas para abelhas (Silveira et al. 2002).

\section{Sistemas reprodutivo e sexual}

Seguindo os métodos estabelecidos por Radford et al. (1974) foram realizados os testes de polinização manual com diferentes tratamentos, utilizando-se no total 54 flores, divididas entre os mesmos. Dessa forma, os seguintes tratamentos foram realizados:

- autopolinização espontânea (autogamia): flores ensacadas e sem tratamento posterior $(\mathrm{n}=$ 12, sendo 6 flores de estilete curto e 6 flores de estilete longo);

- autopolinização manual (autogamia): grãos de pólen depositados no estigma da própria flor (n $=12$, sendo 6 flores de estilete curto e 6 flores de estilete longo);

- polinização cruzada manual (xenogamia): grãos de pólen provenientes de flores de indivíduos diferentes e transferidos para estigmas de flores previamente emasculadas $(\mathrm{n}=18$, sendo 9 flores de estilete curto e 9 flores de estilete longo e 3 tipos de cruzamentos: intermorfos; intramorfo em flores de estilete curto; e intramorfo em flores de estilete longo);

- polinização em condições naturais (controle): flores em pré-antese foram ensacadas e após 24 horas de exposição aos visitantes florais foram coletadas $(n=12$, sendo 6 flores de estilete curto e 6 flores de estilete longo).

Para determinar o sistema reprodutivo, verificou-se a formação de tubos polínicos em cada tratamento efetuado. Para a realização do tratamento de polinização cruzada, o critério adotado foi o de utilizar indivíduos distanciados minimamente 2 metros entre si. Após a polinização manual, as flores foram novamente ensacadas, para impedir o contato com os visitantes florais.

Os pistilos já fixados em FAA foram levados para o laboratório, onde foram lavados em água destilada, seguido de hidróxido de sódio $(\mathrm{NaOH})$, no qual permaneceram por 60 minutos em estufa à $60^{\circ} \mathrm{C}$ para amaciar os tecidos. Lavou-se novamente os pistilos em água destilada e posteriormente os mesmos foram lavados em hipoclorito de sódio durante 3 minutos, voltando para a água destilada após esse período. Após esse procedimento, alguns tecidos que envolvem o ovário foram retirados e o pistilo foi macerado em uma lâmina com gotas do corante azul de anilina. Para visualizá-los, utilizouse a técnica de microscopia de fluorescência (adaptado de Martin 1959).

\section{Resultados}

\section{Morfometria floral}

O comprimento da corola $(\mathrm{p}=0,01)$ e do estilete $(p=0,01)$ diferiram entre os morfos florais, mas o comprimento das anteras não diferiu ( $\mathrm{p}=$ 0,48) (Tab. 1). Assim, pode-se definir dois morfos florais para $S$. melongena a partir do comprimento do estilete: flores de estilete curto e flores de estilete longo (Fig. 1). A corola foi mais comprida em flores de estilete longo em relação às flores de estilete curto $(\mathrm{p}<0,05)$ (Tab. 1).

Os dois morfos florais ocorrem no mesmo indivíduo, porém em diferentes proporções ao longo da floração. Notou-se que nos três meses iniciais de floração, há uma maior quantidade de flores de estilete curto sendo produzidas pela planta, em uma proporção aproximada de $2: 1$, ou seja, ocorre o padrão de duas flores de estilete curto para uma flor de estilete longo e após esse período, essa proporção tende a diminuir, de forma a se tornar 1:1. 
Tabela 1 - Morfometria floral de Solanum melongena L. para corola, antera e estilete $(\mathrm{cm})$ de flores de estilete curto (EC) e flores de estilete longo (EL) (média \pm desvio padrão). * = diferença significativa / ns = diferença não significativa. Table 1 - Floral morphometry of Solanum melongena L. for corolla, anther and styles (cm) of short-style (EC) and long-style flowers (EL) (mean \pm standard deviation). ${ }^{*}=$ significant difference $/ \mathrm{ns}=$ no significant difference.

\begin{tabular}{cccc}
\hline Morfo floral & Corola & Antera & Estilete \\
\hline EC $(\mathrm{n}=30)$ & $3,2 \pm 0,19 *$ & $0,9 \pm 0,06 \mathrm{~ns}$ & $0,3 \pm 0,06 *$ \\
EL $(\mathrm{n}=30)$ & $4,6 \pm 0,19 *$ & $0,9 \pm 0,06 \mathrm{~ns}$ & $1,0 \pm 0,07 *$ \\
\hline
\end{tabular}

Diferenças morfoanatômicas entre os morfos florais foram detectadas quanto às papilas estigmáticas (Fig. 2b,c,d), que em flores de estilete curto se apresentam de forma murcha e seca e em flores de estilete longo são recobertas por extensa mucilagem. A presença de grande quantidade de tricomas na base do estilete foi observada em ambos os morfos (Fig. 2a,e). Referente às anteras e grãos de pólen, não foi detectada diferença quanto ao tamanho e estrutura entre os morfos florais (Fig. 3). A antera possui deiscência poricida, isto é, os grãos de pólen são liberados através de um pequeno poro em seu ápice (Fig. 3a) e, através de observações de fotografias de Microscopia Eletrônica de Varredura com a mesma escala, infere-se que não houve diferença no tamanho dos grãos de pólen provenientes de flor de estilete curto (Fig. 3b) e flor de estilete longo (Fig. 3c).

\section{Biologia floral e visitantes}

Solanum melongena apresenta inflorescências expostas, com duas a quatro flores cada e dez a quinze flores abertas por indivíduo. A antese das flores ocorre no período da manhã, preferencialmente entre $6 \mathrm{~h}$ e $8 \mathrm{~h}$, porém em algumas flores a abertura se dá no decorrer tarde. A senescência, momento em que ocorre o murchamento da corola, se dá aproximadamente três dias após o início da antese. No momento de abertura, a corola se encontra com os lobos posicionados de forma perpendicular, exibindo o androceu e gineceu nas flores de estilete longo e o androceu nas flores de estilete curto, e os poros das anteras estão abertos. Já nas primeiras horas de antese, os grãos de pólen se encontram secos e pulverulentos dentro das anteras, o que possibilita sua liberação. $\mathrm{O}$ estigma também está receptivo
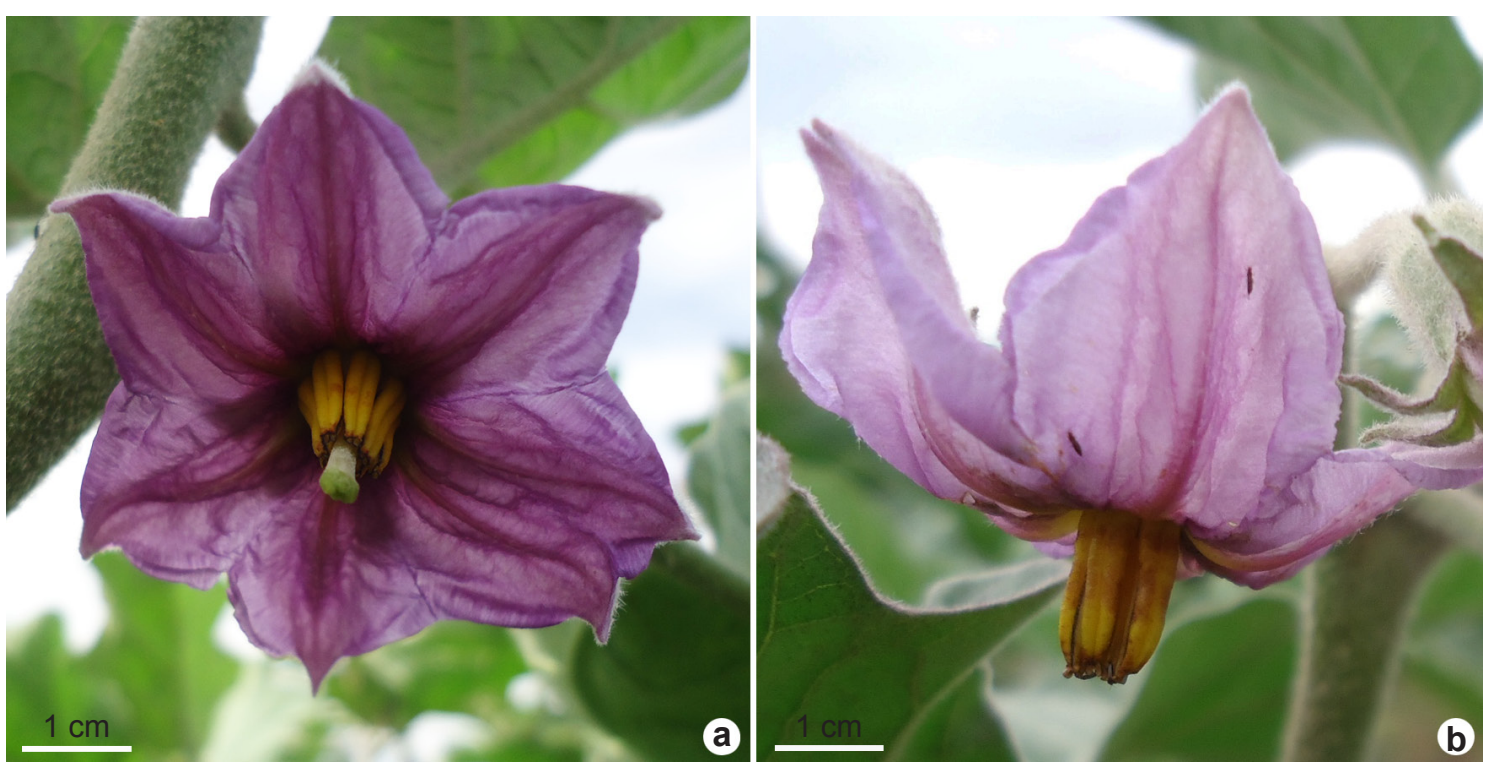

Figura 1 - Diferentes morfos florais de Solanum melongena - a. morfo floral de estilete longo - acima do nível das anteras; b. morfo floral de estilete curto - abaixo do nível das anteras.

Figure 1 - Different floral morphs of Solanum melongena - a. long-style flower - above the level of anthers; b. short-style flower below the level of anthers. 
nesse período e assim permanece até a flor iniciar o processo de senescência, aproximadamente dois dias após o início da antese.

A coloração da corola no momento da antese é lilás, contrastando com as colorações amarela e verde claro das anteras e do estigma, respectivamente. No decorrer da antese, essas colorações vão se modificando, de forma que, após aproximadamente dois dias de ocorrência da mesma, a corola se torna lilás claro, as anteras perdem o amarelo vivo e o estigma adquire uma coloração marrom, em ambos os morfos florais. As flores de estilete longo que não são polinizadas ou fecundadas atrofiam e caem, enquanto as que são fecundadas sofrem um intumescimento no ovário após aproximadamente uma semana, momento em que ocorre também a queda da corola. A maturação do fruto ocorre após 30-50 dias.

Detectou-se a presença de osmóforos nas flores, concentrados nas extremidades da corola
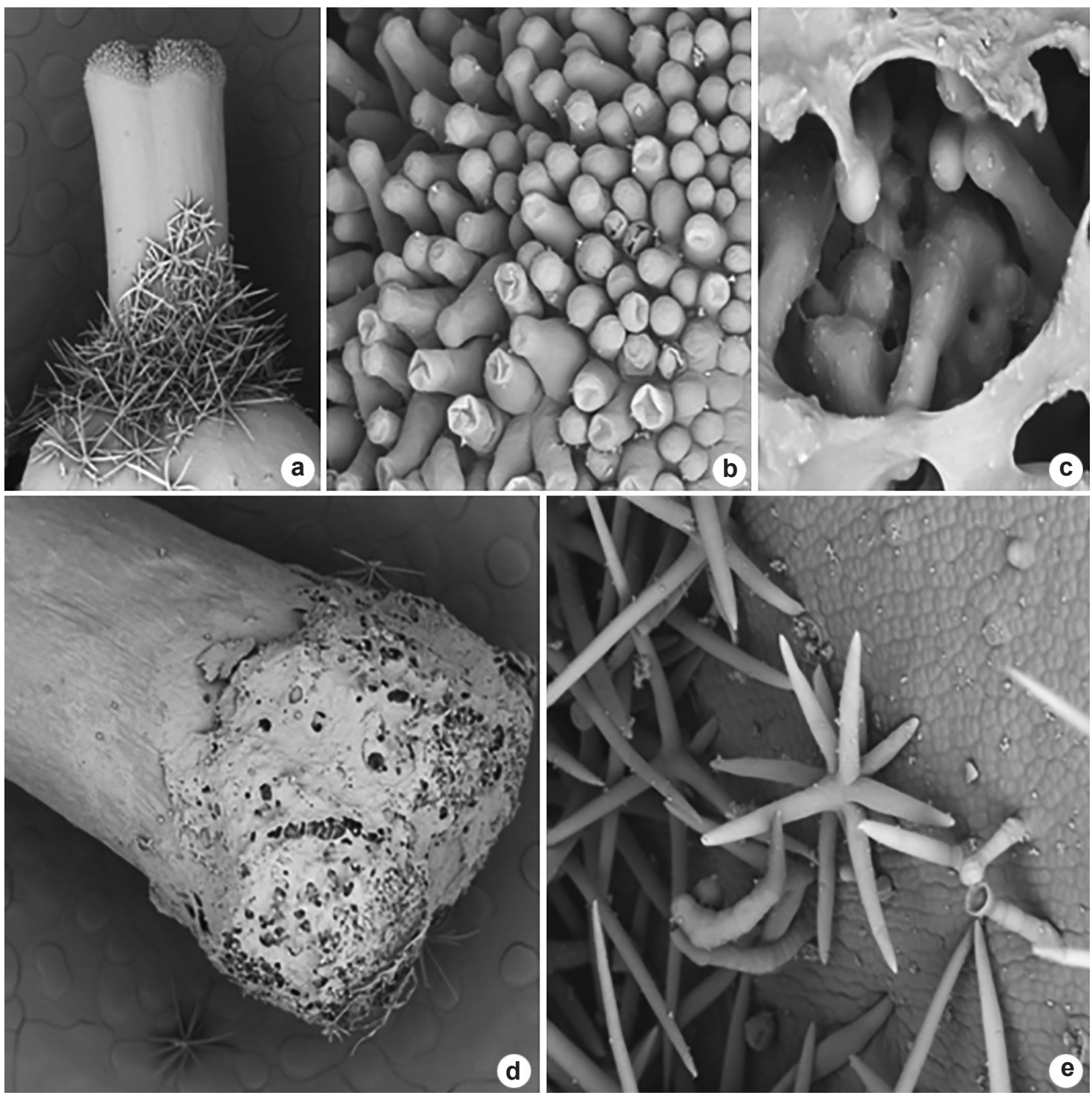

Figura 2 - Estilete e estigma dos diferentes morfos florais de Solanum melongena. - a. pistilo - flor de estile curto (60x); b. papilas estigmáticas - flor de estilete curto $(800 \mathrm{x})$; c. papilas estigmáticas - flor de estilete longo (1.0kx); d. estigma flor de estilete longo (50x); e. tricomas na base de estilete curto (400x).

Figure 2 - Style and stigma of different floral morphs of Solanum melongena. - a. pistil - short-style flower (60x); b. stigmatic papillae - shortstyle flower (800x); c. stigmatic papillae - long-style flower (1.0kx); d. stigma - long-style flower (50x); e. trichomes on short-style base (400x). 

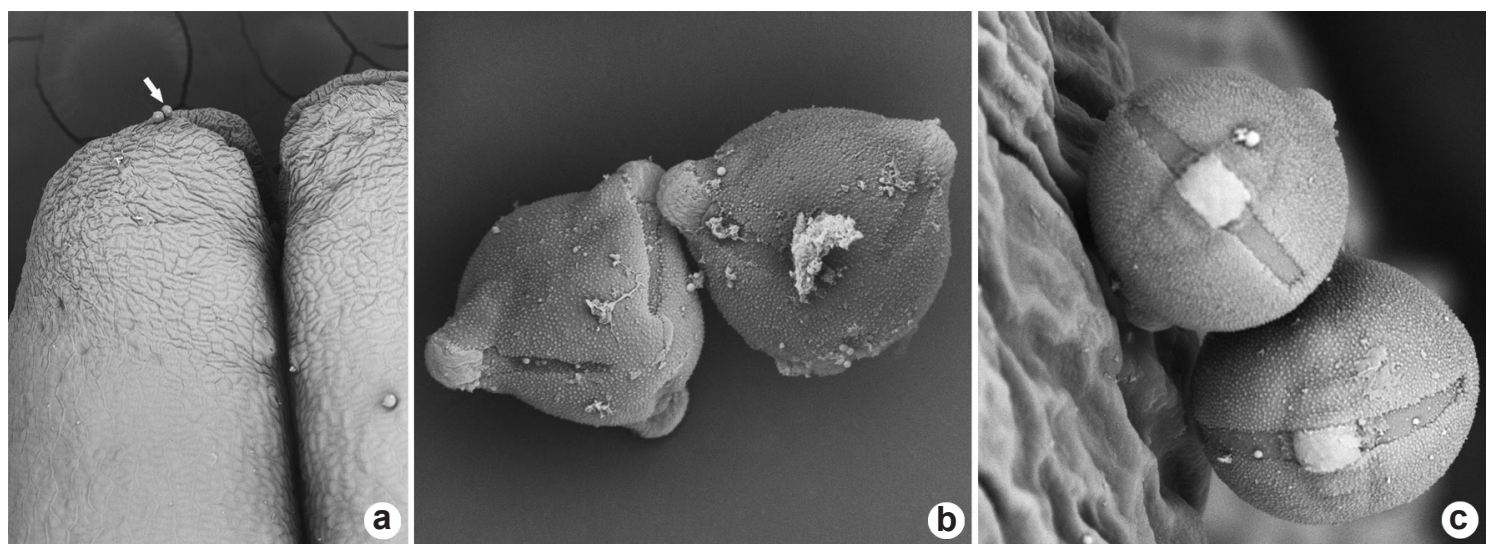

Figura 3 - Antera e grãos de pólen de Solanum melongena - a. detalhe do poro da antera (180x) - seta indicando a presença de grãos de pólen próximos à abertura; b. grão de pólen de antera de flor de estilete curto (300x); c. grão de pólen de antera de flor de estilete longo (300x).

Figure 3 - Solanum melongena anther and pollen grains - a. detail of anther pore (180x) - arrow indicating the presence of pollen grains near opening; b. pollen grain of short-style flower anther (300x); c. pollen grain of long-style flower anther (300x).

e no ápice das anteras. A porcentagem média de viabilidade do pólen foi de aproximadamente $72 \%$, apresentando variações entre os estágios. Constatou-se que tanto em flores de estilete curto $(p=0,0021)$ quanto em flores de estilete longo $(\mathrm{p}=0,0093)$ a viabilidade polínica é dependente do estágio floral, ou seja, nos primeiros estágios florais - que correspondem aos primeiros momentos da antese - há uma maior quantidade de pólen viável, se comparado com o estágio mais próximo do momento da senescência da flor (Tabs. 2; 3). Considerando os altos valores de viabilidade, os grãos de pólen oriundos das anteras dos dois morfos florais são adequados para a fertilização.

Sete espécies de abelhas, pertencentes às famílias Apidae, Halictidae e Andrenidae e uma espécie de mosca da família Syrphidae foram identificadas (Tab. 4). Quanto ao comportamento específico de cada espécie de visitante floral, cinco apresentaram comportamento de vibração, o qual está relacionado à morfologia floral de S. melongena (Tab. 4). Todas as espécies foram observadas visitando ambos os morfos florais. Os visitantes mais frequentes foram Apis mellifera (31,9\%), Xylocopa frontalis (20,8\%) e Exomalopsis diminuta $(15,6 \%)$, sendo mais constantes no período da manhã ( $8 \mathrm{~h}-12 \mathrm{~h}$ ). Embora A. mellifera não tenha apresentado comportamento de vibração como as outras duas espécies mais frequentes, sua forma de se movimentar pela flor possibilita a liberação dos grãos de pólen das anteras, uma vez que a mesma se movimenta de forma a "empurrálas" rápida e repetidamente com a cabeça, o que também a faz contatar o estigma da flor.

A contagem de grãos de pólen nos diferentes horários do dia não indicou a existência de correlação positiva significativa $(r=0,74 ; p$ $=0,62$ ) entre os horários de maior quantidade de pólen e os horários de maior frequência dos visitantes florais (Fig. 4). Após a abertura da flor,

Tabela 2 - Viabilidade polínica de Solanum melongena nos diferentes estágios florais em flores de estilete curto $(\mathrm{n}=20)$ (média \pm desvio padrão).

Table 2 - Pollen viability of Solanum melongena in different floral stages in short-style flowers (mean \pm standard deviation).

\begin{tabular}{cc}
\hline Estágio Floral & Viabilidade dos grãos de pólen (\%) \\
\hline 1 & $78,6 \pm 9,7 \mathrm{ab}$ \\
2 & $89 \pm 20,1 \mathrm{a}$ \\
4 & $60,4 \pm 8,5 \mathrm{bc}$ \\
$4,6 \pm 21,3 \mathrm{c}$ \\
\hline
\end{tabular}

Médias seguidas pela mesma letra não diferem entre si a $\mathrm{p}<0,05$ 
Tabela 3 - Viabilidade polínica de Solanum melongena nos diferentes estágios florais em flores de estilete longo $(\mathrm{n}=20)$ (média \pm desvio padrão).

Table 3 - Pollen viability of Solanum melongena in different floral stages in long-style flowers (mean \pm standard deviation).

\begin{tabular}{cc}
\hline Estágio Floral & Viabilidade dos grãos de pólen (\%) \\
\hline 1 & $90,4 \pm 15,7$ a \\
2 & $88,4 \pm 13,7$ a \\
3 & $73,8 \pm 0,9 \mathrm{a}$ \\
4 & $46,2 \pm 28,5 \mathrm{~b}$ \\
\hline
\end{tabular}

Médias seguidas pela mesma letra não diferem entre si a $\mathrm{p}<0,05$

há uma grande liberação e consumo dos grãos de pólen pela ação dos polinizadores logo nas primeiras 6 horas de antese e, após aproximadamente 9 horas, a disponibilidade de pólen diminui cerca de $50 \%$. Entretanto, ainda observa-se abelhas visitando as flores após esse período e no segundo dia de antese, quando a quantidade de recurso é escassa.

\section{Sistema reprodutivo e sexual}

De maneira geral, em flores de estilete longo o crescimento dos tubos polínicos se iniciou após 12 horas das polinizações e em flores de estilete curto não houve crescimento de tubos polínicos em nenhum dos tratamentos (Fig. 5). Portanto, os resultados a seguir referem-se apenas às flores de estilete longo. No tratamento de autopolinização manual, observou-se grãos de pólen germinando na superfície estigmática após 12 horas, entretanto ainda não havia tubos polínicos alcançando os óvulos, os quais foram observados após 48 horas da realização deste tratamento.

No tratamento de polinização cruzada manual, os resultados obtidos através dos cruzamentos intra (flor de estilete longo $\times$ flor de estilete longo) e inter-morfos (flor de estilete longo $\times$ flor de estilete curto) indicaram a presença de grãos de pólen germinando na superfície estigmática e formação de tubos polínicos ao longo de todo o estilete após 12 horas da polinização (Fig. 5a). Também notou-se tubos alcançando os óvulos após 24 horas da polinização, indicando a fecundação dos mesmos (Fig. 5b,c). Após 48 horas desses tratamentos, visualizou-se uma quantidade reduzida de óvulos sem tubos polínicos penetrando a micrópila, o que indica que grande parte deles foi fecundada.

Tabela 4 - Identificação e comportamento das espécies de visitantes florais observados em cultivo de Solanum melongena no período de fevereiro e junho de 2014 em Estiva Gerbi, São Paulo. PO = polinizador; PI = pilhador; $\mathrm{V}=$ vibra; $\mathrm{NV}=$ não vibra.

Table 4 - Identification and behavior of the species of floral visitors observed in Solanum melongena cultivation between February and June 2014 in Estiva Gerbi, São Paulo. PO = pollinator; PI = nectar thief; V= vibrate; NV = not vibrate.

\begin{tabular}{|c|c|c|}
\hline Insecta & Visitantes florais & Comportamento \\
\hline \multicolumn{3}{|c|}{ HYMENOPTERA ANDRENIDAE } \\
\hline Oxaeini & Oxaea flavescens Klug, 1807 & $\mathrm{PO} / \mathrm{V}$ \\
\hline \multicolumn{3}{|l|}{ APIDAE } \\
\hline Apini & Apis mellifera Linnaeus, 1758 & $\mathrm{PO} / \mathrm{NV}$ \\
\hline Bombini & Bombus morio Swederus, 1787 & $\mathrm{PO} / \mathrm{V}$ \\
\hline Exomalopsini & Exomalopsis diminuta Silveira, 1996 & $\mathrm{PO} / \mathrm{V}$ \\
\hline Meliponini & Trigona spinipes Fabricius, 1793 & $\mathrm{PI} / \mathrm{NV}$ \\
\hline Xylocopini & Xylocopa frontalis Olivier, 1789 & $\mathrm{PO} / \mathrm{V}$ \\
\hline \multicolumn{3}{|l|}{ HALICTIDAE } \\
\hline Augochlorini & Pseudaugochloropsis graminea Fabricius, 1804 & $\mathrm{PO} / \mathrm{V}$ \\
\hline DIPTERA & Syrphidae sp. & $\mathrm{PI} / \mathrm{NV}$ \\
\hline
\end{tabular}




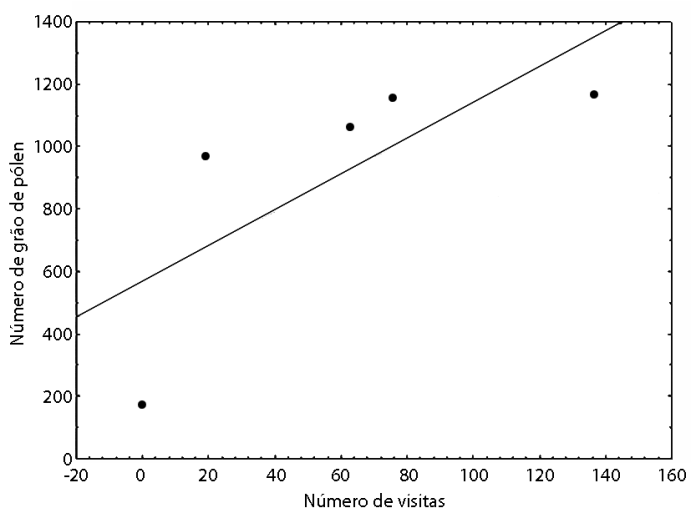

Figura 4 - Disponibilidade de pólen e frequência de visitantes florais ao longo do dia em Solanum melongena. Figure 4 - Pollen availability and floral visitors' frequency throughout the day in Solanum melongena.
Ao serem expostas a condições naturais de campo, as flores de estilete longo apresentaram, após 48 horas do tratamento, grãos de pólen depositados e germinando na superfície estigmática, assim como de tubos polínicos formados ao longo do estilete (Fig. 4d), os quais fecundaram aproximadamente a totalidade de seus óvulos. Não foi possível quantificar o número de tubos polínicos formados ao longo do estilete, bem como os que alcançaram os óvulos, devido à dificuldade em isolá-los, pois muitas vezes os mesmos formavam feixes (Fig. 5d). Não houve formação de tubos polínicos quando realizado o tratamento de autopolinização espontânea em ambos os morfos.

Dessa forma, S. melongena (híbrido Nápoli) pode ser classificada como uma espécie xenógama facultativa, uma vez que mesmo demonstrando
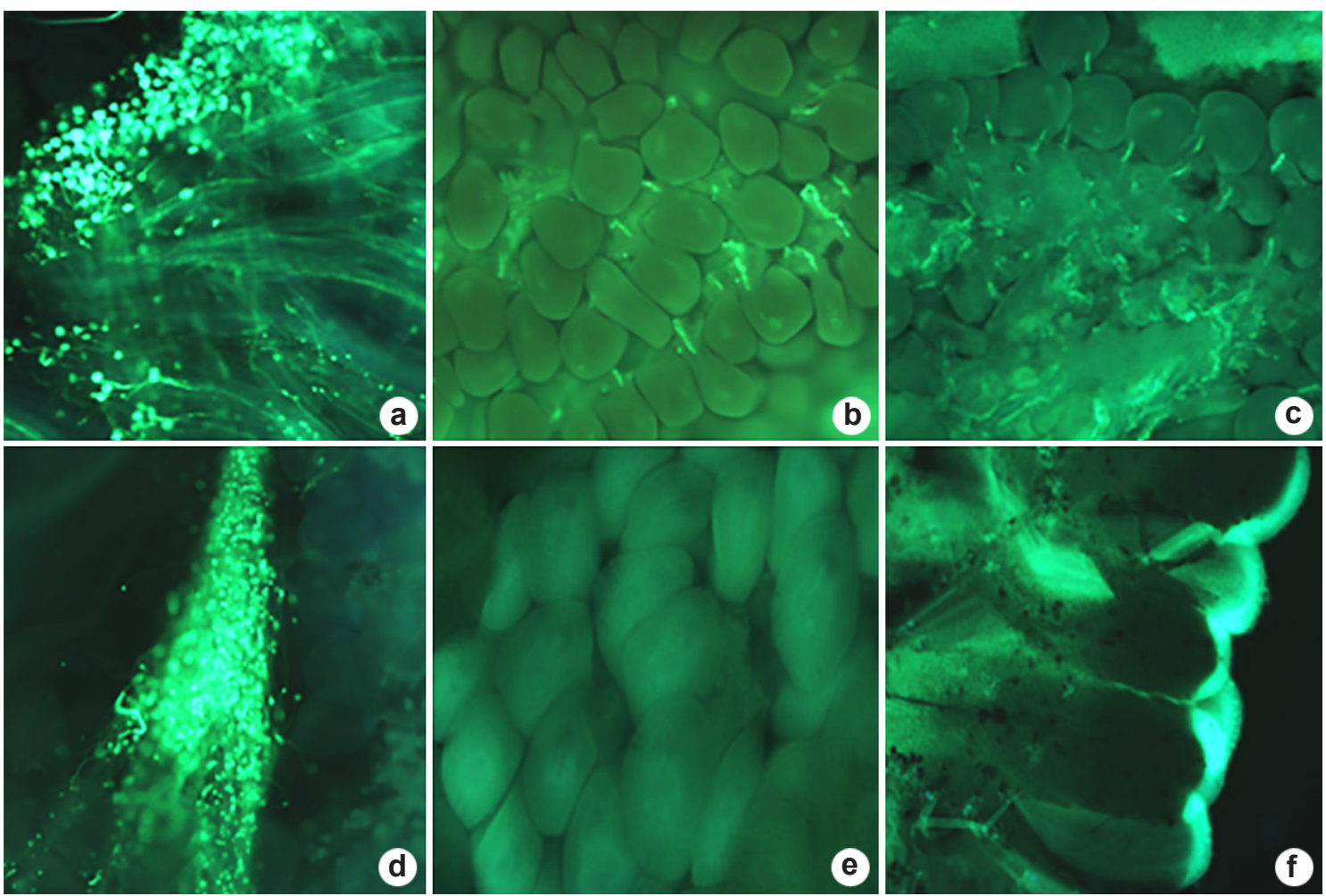

Figura 5 - Formação de tubos polínicos em diferentes tratamentos - a. superfície estigmática de FEL com tubos polínicos formados após 12 horas do tratamento de polinização cruzada - FEL $\times$ FEC; b. óvulos de FEL após 24 horas do tratamento de polinização cruzada - FEL × FEL; c. óvulos de FEL após 24 horas do tratamento de polinização cruzada - FEL $\times$ FEC; d. feixe de tubos polínicos ao longo do estilete de FEL após 48 horas do tratamento de polinização em condições naturais; e. óvulos de FEC após 12 horas do tratamento de polinização cruzada - FEC $\times$ FEC; f. superfície estigmática de FEC após 24 horas do tratamento de polinização em condições naturais. FEL = flor de estilete longo; FEC = flor de estilete curto. Figure 5 - Pollen tube growth in different treatments - a. stigma surface of FEL with pollen tubes formed after 12 hours of cross-pollination treatment - FEL $\times$ FEC; b. ovules of FEL after 24 hours of cross-pollination treatment - FEL $\times$ FEL; c. ovules of FEL after 24 hours of cross-pollination treatment - FEL $\times$ FEC; d. pollen tubes bundle along of style of FEL after 48 hours of pollination in natural conditions treatment; e. ovules of FEC after 12 hours of cross-pollination treatment - FEC $\times$ FEC; f. stigma surface of FEC after 24 hours of natural conditions treatment. FEL = long-style flower; FEC = short-style flower.

Rodriguésia 68(4): 1187-1199. 2017 
certo grau de autocompatibilidade, também há a formação de tubos polínicos alcançando os óvulos na ocorrência de polinização cruzada. Os resultados sugerem também que a fertilização em S. melongena ocorre aproximadamente um dia após a polinização.

\section{Discussão}

Morfometria floral

A espécie estudada já foi classificada como uma espécie heterostílica por alguns autores (Kowalska 2008; Tatis et al. 2009; Nunes-Silva et al. 2010; Nunes-Silva 2011), porém diversas características de sua morfologia floral e de seu sistema sexual não condizem com as características que norteiam o conceito de heterostilia, tais como: hercogamia recíproca nas alturas do estilete e anteras entre os morfos; autoincompatibilidade intra morfo e diferença na quantidade e na morfologia dos grãos de pólen produzidos por cada morfo (Barrett 1998).

No entanto, a utilização de distintos conceitos que definem as características morfológicas de $S$. melongena pode ocorrer devido à existência de variações na espécie. Ocorre uma vasta diversidade genética entre híbridos, cultivares e variedades locais da mesma, o que demonstra a intensa seleção artificial efetuada para melhoramento genético (Araméndiz-Tatis et al. 2011). Tatis et al. (2009) analisando a morfologia floral de dois cultivares da berinjela - Long Purple e Criollo Lila, encontraram grandes diferenças entre eles, sendo que o primeiro apresentou flores tipicamente distílicas e o segundo flores tipicamente tristílicas, ambos com antera e estilete diferindo reciprocamente entre os morfos.

No cultivo estudado com o híbrido Nápoli, não foi encontrado uma quantidade amostral de flores com estilete no mesmo nível das anteras, porém o mesmo já foi relatado, também como raro, em outros estudos com S. melongena, com quantidade aproximada de $15 \%$ do total das flores (Kowalska 2008). Dessa forma, as diferenças encontradas entre os morfos florais neste estudo, podem ocorrer devido às características selecionadas para o desenvolvimento do mesmo.

A diferença aqui observada nas papilas estigmáticas entre os diferentes morfos, corroboram com observações prévias em flores de $S$. melongena (Rylski et al. 1984), em que o estigma de flores de estilete longo possuíam papilas bem desenvolvidas, com tecidos ricos em polissacarídeos, proteínas e outros nutrientes que conferem efetiva germinação de pólen, enquanto flores de estilete curto possuíam estigma com papilas subdesenvolvidas, com pequena quantidade de nutrientes, impossibilitando a germinação dos grãos de pólen. Os tamanhos semelhantes dos grãos de pólen provenientes de ambos os morfos também foram descritos para outras espécies andromonóicas de Solanum (Anderson \& Symon 1989).

Para obtenção de cultivares de alto rendimento, alguns critérios são considerados, como: altura da planta, massa e firmeza do fruto e o número de frutos por indivíduo, que é uma característica priorizada em programas de seleção artificial para melhoramento genético (Tatis et al. 2014). Nesse sentido, embora a produção de flores com estilete curto em maior quantidade que as de estilete longo seja indicada como um fator limitante para determinadas variedades de $S$. melongena, também pode ser vantajosa no início da vida planta, garantindo seu sucesso reprodutivo ao mesmo tempo em que não exige um grande gasto energético. Assim, flores de estilete curto teriam como funções a atração de polinizadores e doação de pólen viável para reprodução.

\section{Biologia floral e visitantes}

A estrutura floral de S. melongena é característica da família Solanaceae e está intimamente relacionada à polinização por vibração (Buchmann \& Hurley 1978). O único recurso disponível é o pólen, que é produzido em grandes quantidades e liberado de maneira gradual durante todo o período de antese, o que possibilita a sua disponibilidade para diversas visitas de abelhas, maximizando sua dispersão, fato que corrobora com as observações em outras espécies de Solanum (Barrett 1998).

Apesar de cerca de 50\% do pólen disponível ser coletado logo no primeiro dia de antese, as abelhas ainda continuavam visitando as flores após esse período. Esse fato corrobora com a ausência de correlação positiva entre os horários de maior frequência dos visitantes florais e os horários de maior disponibilidade de pólen, ou seja, as visitas ocorrem de forma frequente independente da quantidade de pólen disponível. Entretanto, essa diminuição na quantidade do recurso pode acarretar em uma mudança no comportamento das abelhas, que podem passar a girar repetidas vezes sobre a mesma flor e a realizar um número maior de visitas (Buchmann \& Hurley 1978; Shelly \& Villalobos 2000). Abelhas coletoras de pólen são altamente sensíveis à variação da quantidade do mesmo na flor e respondem à sua diminuição com mudanças 
consideráveis no tempo de permanência na flor, que também passa a diminuir (Shelly et al. 2000).

A coloração contrastante dos elementos reprodutivos é uma característica relacionada à atração de abelhas (Kevan \& Baker 1983). Um fator adicional nesse sentido pode ser representado pelos odores emitidos através dos osmóforos, que estão presentes na base das anteras e nas extremidades da corola em S. melongena. A alteração de cores e contrastes da corola, antera e estigma ao longo do período de antese podem constituir indicadores da redução da disponibilidade de recurso, assim como a duração da flor por um período aproximado de três dias pode conferir à espécie um maior sucesso reprodutivo, isto é, maiores chances de haver uma polinização efetiva (Bezerra \& Machado 2003).

A diferença encontrada na viabilidade polínica entre os estágios iniciais e os próximos à senescência da flor pode ser explicada pelo fato de que, ao longo do desenvolvimento, os grãos de pólen tendem a reduzir sua viabilidade, diminuindo sua capacidade de fertilização (Souza et al. 2002). Durante o processo de maturação da planta, a viabilidade do pólen pode ser afetada por vários fatores endógenos ou exógenos, como a fase de desenvolvimento da flor, altas ou baixas temperaturas externas, estado nutricional da planta, luminosidade e até mesmo defensivos agrícolas e outros produtos químicos (Giordano et al. 2003). $\mathrm{Na}$ cultura estudada, pode-se inferir que fatores ambientais podem ter influenciado nesse processo, uma vez que o cultivo perdurava durante todo o ano, sofrendo efeitos da temperatura e luminosidade diversas, assim como a aplicação de defensivos agrícolas, que era efetuada semanalmente.

Quanto aos visitantes florais, considerando que as flores de $S$. melongena apresentam anteras poricidas, as abelhas com comportamento de vibração foram consideradas potenciais polinizadores, uma vez que conseguiam retirar os grãos de pólen efetuando tal comportamento e também visitavam vários indivíduos sequencialmente. A espécie $A$. mellifera, mesmo não apresentando tal comportamento, também pode ser considerada potencial polinizador dessa cultura, uma vez que efetuou o transporte de pólen e contactou as estruturas reprodutivas da flor em suas visitas. Tal fator indica a existência de um processo de aprendizagem por parte da mesma ao manipular as peças florais e coletar o recurso ali presente (Imperatriz-Fonseca et al. 1993).

No entanto, a eficiência de abelhas nativas e da espécie exótica $A$. mellifera na formação de frutos de muitas espécies pode ocorrer de maneira diferenciada, especialmente quanto à qualidade da polinização (Garibaldi et al 2013). Espécies de abelhas nativas costumam visitar flores de muitos indivíduos distanciados entre si e muitas possuem comportamentos específicos, enquanto que a espécie exótica, mesmo sendo capaz de depositar uma grande quantidade de pólen, não apresenta eficiência suficiente para formação de frutos em muitas espécies cultivadas (Garibaldi et al 2013).

\section{Sistemas reprodutivo e sexual}

Constatou-se para $S$. melongena que a grande quantidade de tubos polínicos alcançando os óvulos no tratamento de polinização em condições naturais indica que a mesma apresenta certo nível de dependência de vetores de polinização para se reproduzir sexuadamente. Além disso, levandose em conta que suas flores apresentam anteras poricidas, a liberação de pólen é dificultada na ausência de um visitante floral com comportamento vibratório. Assim, pode-se inferir que a deposição de pólen coespecífico seria de rara ocorrência, devido à sua morfologia floral. Diante desse fator, que chega a impossibilitar totalmente a autopolinização em grande parte de variedades e híbridos da espécie, alguns autores recomendam algumas soluções, como a introdução de caixa de abelhas que possuem comportamento de vibração, a utilização de tratamento com hormônios (Kowalska 2006) e até mesmo a vibração manual das flores (Gemmill-Herren \& Ochieng 2008).

Dessa forma, a existência de um ambiente heterogêneo, que proporcione locais de nidificação, assim como recursos disponíveis para os polinizadores nos momentos em que a cultura agrícola não estiver florescendo, é essencial. A produtividade de um sistema agrícola aumenta com a riqueza de espécies animais e vegetais da comunidade, pois quanto maior for esse número, proporcional será a diversidade de polinizadores com distintos comportamentos, assim como a eficiência dos mesmos em explorar os recursos disponíveis (Tilman et al. 2002).

No caso de $S$. melongena, a qualidade do fruto (peso e número de sementes) e a quantidade de frutos produzidos podem aumentar significativamente na ocorrência da polinização biótica, o que contribui para uma maior rentabilidade da cultura (NunesSilva et al. 2013). Isso acontece porque o padrão de comportamento do polinizador ao depositar e distribuir os grãos de pólen no estigma das flores é mais eficiente do que quando esse processo 
ocorre através do vento ou por mecanismos de autopolinização, que, embora consigam vingar algumas sementes e frutos, não são suficientes para maximizar o potencial produtivo das plantas.

A não formação de tubos polínicos em flores de estilete curto indica uma condição de andromonoicia para S. melongena. A andromonoicia se caracteriza pela apresentação de flores bissexuais e flores funcionalmente masculinas na mesma planta, indicando que a ocorrência de polimorfismo floral é uma característica intrínseca dessa condição de sistema sexual (Anderson \& Symon 1989). Essa condição já foi relatada para outras espécies de Solanum, como S. stramonifolium (Bezerra \& Machado 2003), S. paniculatum (Forni-Martins et al. 1998) e S. lycocarpum (Oliveira-Filho \& Oliveira 1988). Em um estudo com várias espécies do gênero Solanum, concluiu-se para a berinjela uma condição de fracamente andromonóica (Symon 1981).

Nessa perspectiva, pode-se concluir que ambos os morfos florais contribuem igualmente para o sucesso reprodutivo da espécie, uma vez que a polinização cruzada realizada inter-morfos demonstrou-se a mais eficiente na fecundação dos óvulos de flores de estilete longo. Assim, embora tenha-se constatado diferenças entre os verticilos dos diferentes morfos florais, tal fator não demonstrou exercer influência no sucesso reprodutivo da espécie.

Conclui-se também que a riqueza e o comportamento dos polinizadores estão, da mesma maneira, relacionados ao sucesso reprodutivo da espécie, visto que grande parte dos mesmos apresentou comportamento de vibração - relacionado à morfologia floral de S. melongena - e promoveram o transporte de pólen entre os diferentes morfos florais e entre os diferentes indivíduos, realizando a polinização cruzada. E, embora S.melongena (híbrido Nápoli) tenha apresentado certo grau de autogamia, a autopolinização não mostrou-se suficiente para uma efetiva fecundação de seus óvulos como quando na ocorrência da polinização cruzada e em condições naturais.

\section{Agradecimentos}

À Capes, a concessão de bolsa de Mestrado ao primeiro autor; ao Programa de Pós-graduação em Agricultura e Ambiente, Centro de Ciências Agrárias, UFSCar - Campus Araras/SP; e a Iara Bressan, a ajuda com as análises em Microscopia de Fluorescência.

\section{Referências}

Anderson GJ \& Symon DE (1989) Functional dioecy and Andromonoecy in Solanum. Evolution 43: 204-219.

Antonini ACC, Robles WGR, Tessarioli Neto J \& Kluge RA (2002) Capacidade produtiva de cultivares de berinjela. Horticultura Brasileira 20: 646-648.

Araméndiz-Tatis H, Sudré CP, Gonçalves LSA \& Rodrigues R (2011) Potencial agronômico e divergência genética entre genótipos de berinjela nas condições do Caribe Colombiano. Horticultura Brasileira 29: 174-180.

Barrett SCH (1998) The evolution of mating strategies in flowering plants. Trends in Plant Science 3: 335-341.

Barrett SCH, Jesson LK \& Baker AM (2000) The evolution and function of stylar polymorphisms in flowering plants. Annals of Botany 85: 253-265.

Bezerra ELS \& Machado IC (2003) Biologia floral e sistema de polinização em Solanum stramonifolium Jacq. (Solanaceae) em remanescente de Mata Atlântica, Pernambuco. Acta Botanica Brasilica 17: 247-257.

Buchmann SL \& Hurley JP (1978) A biophysical model for buzz pollination in Angiosperms. Journal of Theoretical Biology 72: 639-657.

Dafni A(1992) Pollination ecology: a practical approach. Oxford University Press, New York. 250p.

De Luca PA \& Vallejo-Marín M (2013) What's the "buzz" about? The ecology and evolutionary significance of buzz-pollination. Current Opinion in Plant Biology 16: 429-435.

Forni-Martins ER, Marques MCMM \& Lemes MR (1998) Biologia floral de Solanum paniculatum L. (Solanaceae) no estado de São Paulo, Brasil. Revista Brasileira de Botânica 21: 117-124.

Garibaldi LA, Steffan-Dewenter I, Winfree R, Aizen MA, Bommarco R, Cunningham SA, Kremen C, Carvalheiro LG, Harder LD, Afik O, Bartomeus I, Benjamin F, Boreux V, Cariveau V, Chacoff NP, Dudenhöffer JH, Freitas BM, Ghazoul J, Greenleaf S, Hipólito J, Holzschuh A, Howlett B, Isaacs R, Javorek SK, Kennedy CM, Krewenka KM, Krishnan S, Mandelik Y, Mayfield MM, Motzke I, Munyuli T, Nault BA, Otieno M, Petersen J, Pisanty G, Potts SG, Rader R, Ricketts TH, Rundlöf M, Seymour CL, Schüepp C, Szentgyörgyi H, Taki H, Tscharntke T, Vergara $\mathrm{CH}$, Viana BF, Wanger TC, Westphal C, Willians N \& Klein AM (2013) Wild pollinators enhance fruit set of crops regardless of honey bee abundance. Science 339: 1608-1611.

Gemmill-Herren B \& Ochieng AO (2008) Role of native bees and natural habitats in eggplant (Solanum melongena) pollination in Kenya. Agriculture, Ecosystem and Environment 127: 31-36.

Giordano LB, Aragão FAS \& Boiteux LS (2003) Melhoramento genético do tomateiro. Informe Agropecuário 24: 43-57. 
IBGE - Intituto Brasileiro de Geografia e Estatística (2015) Disponível em <http://www.cidades.ibge. gov.br>. Acesso em 14 janeiro 2015.

Imperatriz-Fonseca VL, Ramalho M \& KleinerlGiovannini A (1993) Abelhas sociais e flores - análise polínica como método de estudo. In: Pirani JR \& Cortapassi-Laurino M (org.) Flores e abelhas em São Paulo. Edusp, São Paulo. Pp. 17-30.

Kearns CA \& Inouye DW (1997) Pollinators, flowering plants, and conservation biology. BioScience 47 : 297-307.

Kevan PG \& Baker HG (1983) Insects as flower visitors and pollinators. Annual Review of Entomology 28: 407-453.

Kowalska G (2006) Eggplant (Solanum melongena L.) flowering and fruiting dynamics depending on pistil type as well as way of pollination and flower hormonization. Folia Horticulturae 18: 17-29.

Kowalska G (2008) Flowering biology of eggplant and procedures intensifying fruit set - review. Acta Scientiarum Polonorum, Horotum Cultus 7: 63-76.

Martin FW (1959) Staining and observing pollen tubes in the style by means of fluorescence. Stain Technology 34: 125-128.

Nunes-Silva P (2011) Capacidade vibratória e polinização por vibração nas abelhas do gênero Melipona (Apidae, Meliponini) e Bombus (Apidae, Bombini). Tese de Dourado. Universidade de São Paulo, São Paulo. 133p.

Nunes-Silva P, Hrncir M \& Imperatriz-Fonseca VL (2010) A polinização por vibração. Oecologia Australis 14: 140-151.

Nunes-Silva P, Hrncir M, Silva CI, Roldão YS \& Imperatriz-Fonseca VL (2013) Stingle bees, Melipona fasciculata, as efficient pollinators of eggplant (Solanum melongena) in greenhouses. Apidologie 44: 537-546.

Oliveira Filho AT \& Oliveira LCA (1988) Biologia floral de uma população de Solanum lycocarpum St. Hill. (Solanaceae) em Lavras MG. Revista Brasileira de Botânica 11: 23-32.

Oliveira PE \& Maruyama PK (2014) Sistemas reprodutivos. In: Rech AR, Agostini A, Oliveira PE \& Machado IC (2014) Biologia da Polinização. Projeto Cultural, Rio de Janeiro. Pp. 71-92.
Radford AE, Dickinson WC, Massey JR \& Bell CR (1974) Vascular plant systematics. Harper \& Row, New York. 891p.

Ribeiro CSC, Brune S \& Reifchneider FJB (1998) Cultivo da berinjela. Embrapa Hortaliças, Brasília. 23p.

Rylski I, Nothmann J \& Arcan L (1984) Differential fertility in short - styled eggplant flowers. Scientia Horticulturae 22: 39-46.

Setzer J (1976) Atlas climático do estado de São Paulo. Secretaria da Agricultura, São Paulo. 98p.

Shelly TE \& Villalobos E (2000) Buzzing bees (Hymenoptera: Apidae, Halictidae) on Solanum (Solanaceae): floral choice and handling time track pollen avaibility. Florida Entomologist 83: 180-187.

Silveira FA, Melo GAR \& Almeida EAB (2002) Abelhas brasileiras - sistemática e identificação. Fernando A. Silveira, Belo Horizonte. 254p.

Souza MM, Pereira TNS \& Martins ER (2002) Microsporogênese e microgametogênese associadas ao tamanho do botão floral e da antera e viabilidade polínica em maracujazeiro-amarelo (Passiflora edulis Sims f. flavicarpa Degener). Ciência Agrotecnologia 26: 1209-1217.

Symon DE (1981) A revision of the genus Solanum in Australia. Journal of the Adelaide Botanic Gardens 4: 1-367.

Tatis HA, Ayala CC \& Camacho ME(2009)Caracterizacíon de La morfología floral de dos cultivares de berinjena (Solanum melongena L.) (Solanaceae). Revista Facultad Nacional de Agronomía Medellín 62: 5125-5134.

Tatis HA, Ayala CC \& Correa-Álvarez E (2014) Parámetros genéticos en berenjena (Solanum melongena L.). Revista U.D.C.A. Actualidad \& Divulgación Científica 17: 361-369.

Teixeira SP, Marinho CR \& Paulino JV (2014) A flor: aspectos morfofuncionais e evolutivos. In: Rech AR, Agostini A, Oliveira PE \& Machado IC. Biologia da Polinização. Projeto Cultural, Rio de Janeiro. Pp. 45-69.

Tilman D, Cassman KG, Matson PA, Naylor R \& Polasky S (2002) Agricultural sustainability and intensive production practices. Nature 418: 671-677

Vilhena AMGF \& Augusto SC (2007) Polinizadores da aceroleira Malpighia emarginata DC (Malpighiaceae) em área de cerrado no Triângulo Mineiro. Bioscience Journal 23: 14-23. 